\title{
Physicochemical Properties of Rice Starch during Microwave Heating for Food Product Quality
}

\author{
Nucharee KrongWORAKUL ${ }^{1}$ and Onanong NAIVIKUL ${ }^{1,2, *}$ \\ ${ }^{1}$ Department of Food Science and Technology, Kasetsart University, Bangkok 10900 Thailand \\ ${ }^{2}$ Associate Fellows, Academy of Science, Office of The Royal Society, Bangkok 10300 Thailand
}

\begin{abstract}
Summary Rice starch is gradually used as a food ingredient. The characteristics of native starch are limited for using in some products. Therefore, microwave heating which is a nonchemically method was used for modify rice starch in this study. Changing of rice starch properties during microwave heating was investigated aimed for improving food product quality. Pasting properties of native starch (NS) showed the highest value for pasting temperature $\left(66.8^{\circ} \mathrm{C}\right.$ ) and pasting viscosity (peak $=3,583 \mathrm{cP}$, trough $=1,542 \mathrm{cP}$, final $=2,805 \mathrm{cP}$ and setback $=956 \mathrm{cP}$ ) than microwave treated rice starch (MRS) at 4 different time periods $(10 \mathrm{~s}, 20 \mathrm{~s}, 30 \mathrm{~s}$ and $40 \mathrm{~s})$. The results of pasting viscosity among MRS at 4 different time periods showed the lower values when increasing heating time. MRS at $40 \mathrm{~s}$ (MRS_40S) gave the lowest pasting temperature $\left(52.9^{\circ} \mathrm{C}\right)$ which was needed lower temperature to gelatinize starch. NS had significant lower To $\left(60.0^{\circ} \mathrm{C}\right)$, Tp $\left(68.8^{\circ} \mathrm{C}\right)$, and $\mathrm{Tc}\left(75.5^{\circ} \mathrm{C}\right)$, and higher enthalpy $(12.22 \mathrm{~J} / \mathrm{g})$ than the MRS. To, Tp and Tc of MRS was increased when treated time increasing, while enthalpy was decreased due to starch was gradually gelatinized and loss of crystallinity. XRD patterns of NS were found to be A-type because it showed peak of $2 \theta$ at $15^{\circ}, 17^{\circ}, 18^{\circ}$ and $23^{\circ}$ while XRD pattern of MRS_40S was changed and displayed peak only at $2 \theta$ (V-type). These changing of XRD patterns may due to loss of crystallinity during heating. The results indicated that microwave heating could change rice starch properties, especially MRS_40S displayed complete gelatinization. In addition, MRS_40S could be applied for using as texture improver for some food products which needs low viscosity e.g. soup, curry sauces and some beverages.
\end{abstract}

Key Words Rice, starch, microwave heating, food quality

Rice starch is gradually used in food industry because it given advantage more than other cereal starches. Its characteristics which included bland taste, white color and small granule size could provide excellent mouthfeel and flavor profiles in the manufacture of smooth gravies, sauces and puddings (1). Normally, rice starch properties are depending on rice variety, protein content, preparation method and modification. There are many studies in literature to modify native rice starch in order to improve its quality. Physicochemical modification is one of popular method. For example, heat treatments at various moisture levels affect starch properties, including paste stability to heat, shear and storage (2). In this research, aimed to compare the effect of microwave heating on physicochemical properties and X-ray diffraction patterns to NS in order to improve viscosity of food products.

\section{Materials and Methods}

1. Preparation of microwave treated rice starch (MRS) Brown rice flour (200 g) from Khao Dawk Mali 105, has $12 \%$ amylose content and low gelatinization temperature (3), was using alkali extraction method (4) to isolate starch. Twenty gram of isolated rice starch was

\footnotetext{
*To whom correspondence should be addressed.

E-mail: fagionn@ku.ac.th
}

mixed with distilled water as starch-water ratio of $1: 2$ and then heated using a Toshiba microwave oven, model ER-G8C, with output power of $600 \mathrm{~W}$ at the frequency of 2,450 MHz. The isolated rice starch samples were heated using microwave oven at 4 different time periods; $10 \mathrm{~s}$ (MRS_10S), $20 \mathrm{~s}$ (MRS_20S), $30 \mathrm{~s}$ (MRS_30S) and $40 \mathrm{~s}$ (MRS_40S). The temperatures of rice starch suspension were measured and recorded during heating using fiber optic probes. All MRS samples were freezedried and stored at room temperature until further analyses.

2. Determination in physico-chemical properties

\subsection{Pasting properties}

NS, MRS_10S, MRS_20S, MRS_30S and MRS_40S were characterized pasting properties of rice flour using a Rapid Visco Analyser (Newport Scientific Pty.Ltd, Warrie-wood, NSW, Australia) following the method of Lee et al. (5). The result of pasting temperature (temperature at initial viscosity increase), peak time (time to peak viscosity), pasting viscosity (peak, trough, final, breakdown and setback) were compared.

\subsection{Thermal properties}

Thermal properties of NS, MRS_10S, MRS_20S, MRS_30S and MRS_40S were determined using a differential scanning calorimeter (DSC 4000, Perkin-Elmer Co., Norwalk, CT) following the method of Patindol and Wang (6). Onset gelatinization (To), peak (Tp) and con- 
clusion (Tc) temperature were determined. The gelatinization enthalpy of each sample was calculated from the surface of endothermic peak area.

\section{Determination on X-ray diffraction patterns}

The X-ray diffraction patterns of NS, MRS_10S, MRS_20S, MRS_30S and MRS_40S were obtained using a diffractometer (PW1830 MPD, Philips, Almelo, The Netherlands) equipped with a copper anode X-ray tube. The diffractometer were operated at $45 \mathrm{kV}, 40 \mathrm{~mA}$ and the spectra was scanned over a diffraction angle

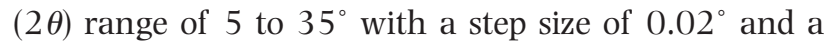
count time of $1 \mathrm{~s}(6)$.

\section{Results and Discussion}

1. Temperature profile of rice starch during heating

During heating in microwave oven, the temperature of rice starch suspension was measured. The heating

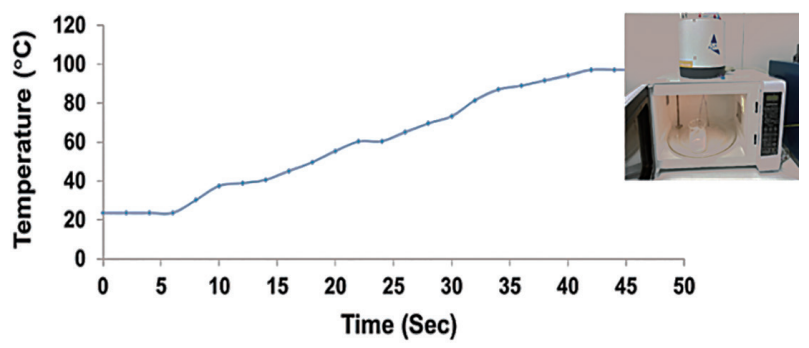

Fig. 1. Temperature profile of NS and MRS during microwave heating. mechanism from microwave oven caused by dielectric properties of rice starch and water in suspension. Figure 1 shows the temperature profile (from $20^{\circ} \mathrm{C}$ to $95^{\circ} \mathrm{C}$ ) of rice starch suspensions which indicated that the temperature was increased after heating for $8 \mathrm{~s}$ $\left(30^{\circ} \mathrm{C}\right.$ ) reached to $70^{\circ} \mathrm{C}$ (started gelatinization temp) at $28 \mathrm{~s}$ and the final temperature of $95^{\circ} \mathrm{C}$ at $40 \mathrm{~s}$. The results showed that rice starch suspension could be gelatinized in microwave oven with short time and fully gelatinized at $40 \mathrm{~s}$.

\section{Physico-chemical properties}

2.1 Pasting properties

Table 1 shows pasting properties of NS, MRS_10S, MRS_20S, MRS_30S and MRS_40S. The NS displayed the highest pasting viscosity (peak $=3,583 \mathrm{cP}$, trough $=1,542 \mathrm{cP}$, final $=2,805 \mathrm{cP}$ and setback $=956$ cP) while MRS_40S gave the lowest pasting viscosity $($ peak $=1,593 \mathrm{cP}$, trough $=834 \mathrm{cP}$, final $=1,730 \mathrm{cP}$, breakdown $=633 \mathrm{cP}$ and setback $=770 \mathrm{cP}$ ). Pasting viscosity of MRS was low while increased heating time to $20 \mathrm{~s}, 30 \mathrm{~s}$ and $40 \mathrm{~s}$. The changes in pasting viscosity of MRS were probably due to starch was pre-gelatinized.

2.2 Thermal properties

Table 2 shows thermal properties of NS, MRS_10S, MRS_20S, MRS_30S and MRS_40S. To of MRS were significantly different compared with NS $(p<0.05)$. The To of rice starch was higher when increased heating time, while the enthalpy was lower. NS displayed the lowest To $\left(60^{\circ} \mathrm{C}\right)$ but the highest enthalpy $(12.22 \mathrm{~J} / \mathrm{g})$. The MRS_40S gave the highest To $\left(81.11^{\circ} \mathrm{C}\right)$, Tp $\left(81.36^{\circ} \mathrm{C}\right)$

Table 1. Pasting properties of NS and MRS during microwave heating.

\begin{tabular}{lccccccc}
\hline \multirow{2}{*}{$\begin{array}{c}\text { Type of } \\
\text { starch }\end{array}$} & $\begin{array}{c}\text { Pasting temp. } \\
\left({ }^{\circ} \mathrm{C}\right)\end{array}$ & $\begin{array}{c}\text { Peak time } \\
(\mathrm{min})\end{array}$ & & \multicolumn{5}{c}{ Viscosity $(\mathrm{cP})$} \\
\cline { 4 - 8 } & & & & \multicolumn{5}{c}{ Peak } & Trough & Break down & Final & Set back \\
\hline NS & $66.8 \pm 0.0 \mathrm{a}$ & $8.6 \pm 0.0 \mathrm{~ns}$ & $3,583 \pm 6 \mathrm{a}$ & $1,542 \pm 3 \mathrm{a}$ & $1,736 \pm 3 \mathrm{a}$ & $2,805 \pm 22 \mathrm{a}$ & $956 \pm 18 \mathrm{a}$ \\
MRS_10S & $66.0 \pm 0.0 \mathrm{a}$ & $8.6 \pm 0.0 \mathrm{~ns}$ & $3,181 \pm 50 \mathrm{~b}$ & $1,106 \pm 55 \mathrm{~b}$ & $1,733 \pm 97 \mathrm{a}$ & $2,365 \pm 54 \mathrm{~b}$ & $917 \pm 9 \mathrm{ab}$ \\
MRS_20S & $65.2 \pm 0.1 \mathrm{ab}$ & $8.8 \pm 0.0 \mathrm{~ns}$ & $2,736 \pm 52 \mathrm{c}$ & $1,027 \pm 55 \mathrm{bc}$ & $1,476 \pm 95 \mathrm{ab}$ & $2,171 \pm 47 \mathrm{c}$ & $912 \pm 4 \mathrm{ab}$ \\
MRS_30S & $63.8 \pm 1.0 \mathrm{~b}$ & $9.0 \pm 0.1 \mathrm{~ns}$ & $2,215 \pm 160 \mathrm{~d}$ & $956 \pm 4 \mathrm{bc}$ & $1,128 \pm 123 \mathrm{~b}$ & $1,952 \pm 68 \mathrm{~d}$ & $865 \pm 31 \mathrm{~b}$ \\
MRS_40S & $52.9 \pm 0.0 \mathrm{c}$ & $8.3 \pm 0.6 \mathrm{~ns}$ & $1,593 \pm 203 \mathrm{e}$ & $834 \pm 91 \mathrm{c}$ & $633 \pm 211 \mathrm{bc}$ & $1,730 \pm 14 \mathrm{e}$ & $770 \pm 6 \mathrm{c}$ \\
\hline
\end{tabular}

NS=Native starch, MRS_10S=Microwave treated rice starch for $10 \mathrm{~s}$, MRS_20S=Microwave treated rice starch for $20 \mathrm{~s}$, MRS_30S=Microwave treated rice starch for $30 \mathrm{~s}$, MRS_40S=Microwave treated rice starch for $40 \mathrm{~s}$.

a Means value (SD) with different small letters in same column are significantly different $(p<0.05)$.

Table 2. Thermal properties of NS and MRS during microwave heating.

\begin{tabular}{lcccc}
\hline Type of starch & To $\left({ }^{\circ} \mathrm{C}\right)$ & $\mathrm{Tp}\left({ }^{\circ} \mathrm{C}\right)$ & $\mathrm{Tc}\left({ }^{\circ} \mathrm{C}\right)$ & $\mathrm{DH}(\mathrm{J} / \mathrm{g})$ \\
\hline NS & $60.00 \pm 0.93 \mathrm{c}$ & $68.73 \pm 0.14 \mathrm{c}$ & $75.49 \pm 0.51 \mathrm{c}$ & $12.22 \pm 0.07 \mathrm{a}$ \\
MRS_1OS & $60.61 \pm 0.10 \mathrm{~b}$ & $67.63 \pm 0.11 \mathrm{~d}$ & $74.52 \pm 0.60 \mathrm{c}$ & $11.12 \pm 0.03 \mathrm{a}$ \\
MRS_20S & $62.27 \pm 0.23 \mathrm{~b}$ & $68.61 \pm 0.18 \mathrm{c}$ & $75.19 \pm 0.26 \mathrm{c}$ & $7.77 \pm 1.01 \mathrm{~b}$ \\
MRS_30S & $79.38 \pm 0.24 \mathrm{a}$ & $79.72 \pm 0.20 \mathrm{~b}$ & $80.81 \pm 0.51 \mathrm{~b}$ & $0.44 \pm 0.14 \mathrm{c}$ \\
MRS_4OS & $81.11 \pm 0.44 \mathrm{a}$ & $81.36 \pm 0.35 \mathrm{a}$ & $82.64 \pm 0.21 \mathrm{a}$ & $0.13 \pm 0.01 \mathrm{c}$ \\
\hline
\end{tabular}

NS=Native starch, MRS_10S=Microwave treated rice starch for $10 \mathrm{~s}$, MRS_20S=Microwave treated rice starch for $20 \mathrm{~s}$, MRS_30S=Microwave treated rice starch for $30 \mathrm{~s}$, MRS_40S=Microwave treated rice starch for $40 \mathrm{~s}$.

a Means value (SD) with different small letters in same column are significantly different $(p<0.05)$. 


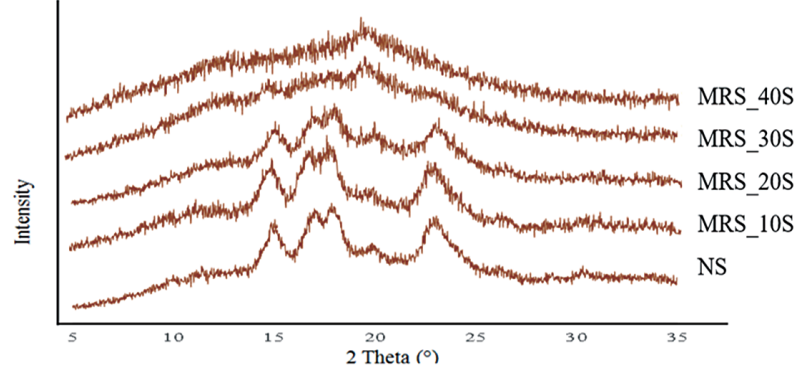

Fig. 2. X-ray diffraction patterns of NS and MRS during microwave heating. NS=Native starch, MRS_10S= Microwave treated rice starch for $10 \mathrm{~s}$, MRS_20S= Microwave treated rice starch for $20 \mathrm{~s}$, MRS_30S= Microwave treated rice starch for $30 \mathrm{~s}$, MRS_40S= Microwave treated rice starch for $40 \mathrm{~s}$.

and Tc $\left(82.64^{\circ} \mathrm{C}\right)$. During heating, the NS was gelatinized and loss of crystallinity so that the enthalpy of starch samples were lower when increased heating time (7). The similar results were found in this research for both NS and MRS rice starch samples.

3. X-ray diffraction patterns

XRD pattern of NS, MRS_10S, MRS_20S, MRS_30S and MRS_40S are shown in Fig. 2. NS displayed a typical A-type pattern with peaks at $2 \theta=15^{\circ}, 17^{\circ}, 18^{\circ}$ and $23^{\circ}$. When increased heating time, XRD pattern of rice starch was changed caused by the loss of crystallinity, especially MRS_4OS had only peak at $2 \theta=20^{\circ}$. The results of peak at $2 \theta=20^{\circ}$ indicated that the crystalline type of rice starch could be changed from A-type (native) to V-type after microwave heating for $40 \mathrm{~s}$. The V-type could be found in amylose helical complex starch after gelatinization and complex with other components and the V-amylose complex starch have shown potential for modify starch rheological functionality $(8,9)$.

\section{Conclusion}

Physicochemical properties (pasting viscosity and thermal properties) of NS were changed during microwave heating. The pasting viscosity and thermal enthalpy of NS was low while increased heating time. MRS_40S gave the lowest pasting viscosity, displayed the highest To, Tp, Tc and the lowest thermal enthalpy. XRD pattern of NS (A-type) was changed and MRS_40S showed peak of $2 \theta$ only at $20^{\circ}$ (V-type) which might be due to microwave heating could lose crystalline of native starch. The results indicated that microwave heating changes rice starch properties and could be used to modify rice starch by using shorter time than normal method. In addition, it suggests that MRS_40S could be used for improving some low viscosity food products e.g. soups, curry sauces and some beverages.

\section{Disclosure of State of COI \\ No conflicts of interest to be declared.}

\section{Acknowledgments}

This work was supported for facilities and equipment by the Department of Food Science at University of Arkansas (Fayetteville, USA) and the Innovation Laboratory at CPF Food and Beverage Co., Ltd. (Nongjok), which are gratefully acknowledged.

\section{REFERENCES}

1) Mitchell CR. 2009. Rice starches: production and properties In Starch chemistry and technology 3rd edition, $p$ 569-578. Academic Press, Amsterdam.

2) Mason WR. 2009. Starch use in foods In Starch chemistry and technology 3rd edition, p 745-795. Academic Press. Amsterdam.

3) Bureau of Rice Research and Department. 2010. Khao Dawk Mali 105, p 8-17. Source: http://brrd.ricethai land.go.th/library/document/E-book/brrd5301007c1. pdf

4) Suksomboon A, Naivikul O. 2006. Effect of dry- and wet-milling processes on chemical, physicochemical properties and starch molecular structures of rice starches. Kasetsart J Nat Sci 40: 125-134.

5) Lee S-W, Lee J-H, Han S-H, Lee J-W, Rhee C. 2005. Effect of various processing methods on the physical properties of cooked rice and on in vitro starch hydrolysis and blood glucose response in rats. Starch/Stärke 57: 531-539.

6) Patindol J, Wang Y-J. 2003. Fine structures and physicochemical properties of starches from chalky and translucent rice kernels. J Agric Food Chem 51: 2777-2784.

7) Colonna P, Buleon A. 2010. Thermal transitions of starches in Starches: characterization, properties and application, p 71-102, CRC Press, New York.

8) Nuessli J, Conde-Petit B, Trommsdorff UR, Escher F. 1995. Influence of starch flavour interactions on rheological properties of low systems concentration starch. Carbohydr Polym 28: 167-470.

9) D'Silva TV, Taylor JRN, Emmambux MN. 2011. Enhancement of pasting properties of teff and maize starches through wet-heat processing with added stearic acid. Journal of Cereal Science 53: 192-197. 